Author affiliations and support information (if applicable) appear at the end of this article.

Published at jco.org on September 19, 2016.

Processed as a Rapid Communication manuscript.

Corresponding author: Matthew D. Hellmann, MD, Memorial Sloan Kettering Cancer Center, 300 E 66th St, New York, NY 10065; e-mail: hellmanm@mskcc.org. (C) 2016 by American Society of Clinical Oncology

0732-183X/17/3507w-709w/\$20.00

\title{
Pneumonitis in Patients Treated With Anti-Programmed Death-1/Programmed Death Ligand 1 Therapy
}

Jarushka Naidoo, Xuan Wang, Kaitlin M. Woo, Tunc Iyriboz, Darragh Halpenny, Jane Cunningham, Jamie E. Chaft, Neil H. Segal, Margaret K. Callahan, Alexander M. Lesokhin, Jonathan Rosenberg, Martin H. Voss, Charles M. Rudin, Hira Rizvi, Xue Hou, Katherine Rodriguez, Melanie Albano, Ruth-Ann Gordon, Charles Leduc, Natasha Rekhtman, Bianca Harris, Alexander M. Menzies, Alexander D. Guminski, Matteo S. Carlino, Benjamin Y. Kong, Jedd D. Wolchok, Michael A. Postow, Georgina V. Long, and Matthew D. Hellmann

\section{$\begin{array}{llllllll}\text { A } & \text { B } & \mathbf{S} & \mathbf{T} & \mathbf{R} & \mathbf{A} & \mathbf{C} & \mathbf{T}\end{array}$}

\section{Purpose}

Pneumonitis is an uncommon but potentially fatal toxicity of anti-programmed death-1 (PD-1)/ programmed death ligand 1 (PD-L1) monoclonal antibodies (mAbs). Clinical, radiologic, and pathologic features are poorly described.

\section{Methods}

Patients who received anti-PD-1/PD-L1 monotherapy or in combination with anti-cytotoxic T-cell lymphocyte-4 mAb were identified at two institutions (Memorial Sloan Kettering Cancer Center: advanced solid cancers, 2009 to 2014, and Melanoma Institute of Australia: melanomas only, 2013 to 2015). Pneumonitis was diagnosed by the treating investigator; cases with confirmed malignant lung infiltration or infection were excluded. Clinical, radiologic, and pathologic features of pneumonitis were collected. Associations among pneumonitis incidence, therapy received, and underlying malignancy were examined with Fisher's exact test as were associations between pneumonitis features and outcomes.

\section{Results}

Of 915 patients who received anti-PD-1/PD-L1 mAbs, pneumonitis developed in 43 (5\%; 95\% Cl, 3\% to 6\%; Memorial Sloan Kettering Cancer Center, 27 of 578 [5\%]; Melanoma Institute of Australia, 16 of 337 [5\%]). Time to onset of pneumonitis ranged from 9 days to 19.2 months. The incidence of pneumonitis was higher with combination immunotherapy versus monotherapy (19 of 199 [10\%] $v 24$ of 716 [3\%]; $P<.01$ ). Incidence was similar in patients with melanoma and non-small-cell lung cancer (overall, 26 of 532 [5\%] $v$ nine of 209 [4\%]; monotherapy, 15 of $417 v$ five of 152 [ $P=1.0$ ]; combination, 11 of $115 v$ four of 57 [ $P=.78]$ ). Seventy-two percent (31 of 43) of cases were grade 1 to 2, and 86\% (37 of 43) improved/resolved with drug holding/immunosuppression. Five patients worsened clinically and died during the course of pneumonitis treatment; proximal cause of death was pneumonitis $(n=1)$, infection related to immunosuppression $(n=3)$, or progressive cancer $(n=1)$. Radiologic and pathologic features of pneumonitis were diverse.

\section{Conclusion}

Pneumonitis associated with anti-PD-1/PD-L1 mAbs is a toxicity of variable onset and clinical, radiologic, and pathologic appearances. It is more common when anti-PD-1/PD-L1 mAbs are combined with anti-cytotoxic T-cell lymphocyte-4 mAb. Most events are low grade and improve/ resolve with drug holding/immunosuppression. Rarely, pneumonitis worsens despite immunosuppression, and may result in infection and/or death.

\section{J Clin Oncol 35:709-717. (C) 2016 by American Society of Clinical Oncology}

\section{INTRODUCTION}

Anti-programmed death-1 (anti-PD-1) and antiprogrammed death ligand 1 (anti-PD-L1) monoclonal antibodies (mAbs) for patients with multiple malignancies are now Food and Drug Administration-approved therapies, which include nivolumab and pembrolizumab for melanoma ${ }^{1,2}$ and non-small-cell lung cancer (NSCLC), ${ }^{3-6}$ nivolumab for renal cell carcinoma ${ }^{7}$ and Hodgkin lymphoma, ${ }^{8}$ atezolizumab for bladder cancer, ${ }^{9}$ and nivolumab plus ipilimumab for melanoma. ${ }^{10}$ These agents also have been studied in other diseases ${ }^{11-13}$ along with durvalumab (PD-L1 mAb) and tremelimumab (cytotoxic T-cell lymphocyte-4 [CTLA-4] $\mathrm{mAb}){ }^{14,15}$ One of the remarkable characteristics of anti-PD-1/PD-L1 mAbs is their relatively mild 
toxicity profile. However, immune-related adverse events can occur and may be severe. ${ }^{16,17}$ Pneumonitis is an immune-related adverse event that accounted for three deaths in an early-phase study with an anti-PD-1 mAb. ${ }^{18}$

Pneumonitis is defined as a focal or diffuse inflammation of the lung parenchyma, ${ }^{19}$ and its incidence in studies with anti-PD-1/ PD-L1 mAbs has ranged from $0 \%$ to $10 \%{ }^{20}$ Drug-related pneumonitis can also occur with chemotherapy (docetaxel, ${ }^{21}$ gemcitabine, ${ }^{22}$ bleomycin ${ }^{23}$ ), targeted therapy (epidermal growth factor receptor inhibitors, ${ }^{24,25}$ mammalian target of rapamycin inhibitors ${ }^{26}$ ), and radiation therapy. ${ }^{27,28}$ Previous experience with these pneumonitides highlighted that clinical, radiologic, and pathologic characterization may facilitate early recognition, treatment optimization, and improved outcomes. The underlying etiology and mechanisms of pneumonitis associated with anti-PD-1/PD-L1 mAbs are unknown.

With the recent approval of anti-PD-1/PD-L1 mAbs, and several other anticipated indications, use is expected to expand rapidly. A critical need exists to gain familiarity with the clinical features of pneumonitis and to optimize management. The clinical experience of patients with anti-PD-1/PD-L1-associated pneumonitis has not been comprehensively described, and data are sparse with regard to management and outcomes. We describe the clinical, radiologic, and pathologic features and management of 43 cases of pneumonitis as a result of anti-PD-1/PD-L1 mAbs from two separate institutions.

\section{METHODS}

\section{Patients}

After institutional review board approval, patients treated with antiPD-1/PD-L1 mAbs either as monotherapy or in combination with anti-CTLA-4 $\mathrm{mAb}$ were identified from Memorial Sloan Kettering Cancer Center (MSKCC; January 2009 to September 2014; all advanced cancers) and the Melanoma Institute of Australia (MIA) and affiliated hospitals (January 2013 to August 2015; melanomas only). Anti-PD-1/PD-L1 mAbs were delivered either as part of an institutional review board-approved therapeutic study or as an expanded access program. Patients treated concurrently with chemotherapy, targeted therapy, and immunotherapy other than anti-CTLA- $4 \mathrm{mAb}$, and in whom the treatment received was still blinded, were excluded. Cases were identified and reviewed retrospectively (MSKCC, J.N., H.R., X.H., M.D.H.; MIA, X.W., A.M.M., A.D.G., M.S.C., B.Y.K., G.V.L.). Those with a clear alternative etiology, such as proven malignant lung infiltration or active lung infection, were excluded. Grading was performed by the treating investigator in real time by using Common Toxicity Criteria for Adverse Events (version 4.0); the reported grade refers to the highest grade of pneumonitis experienced.

\section{Methods}

For all patients, the treatment regimen received (anti-PD-1/PD-L1 monotherapy or combination with anti-CTLA-4 mAb) and primary tumor site were recorded. In patients with pneumonitis, the following data were collected retrospectively: demographics, prior oncologic therapy, clinical features of pneumonitis, and pneumonitis treatment. Clinical and radiologic outcomes were classified as completely resolved, improved, or worsened. Patients in whom recurrent pneumonitis developed, either with or without drug rechallenge, were noted. Assessment of final clinical outcomes as well as highest grade of pneumonitis included periods of recurrent pneumonitis, if applicable.

Retrospective radiology review of the serial chest computed tomography (CT) scans of patients with pneumonitis was performed in the MSKCC cohort by two independent radiologists (T.I., J.C.) blinded to patient clinical data followed by a consensus read if there was disagreement. Each radiologist described the phenotypic appearance and severity of pneumonitis by using criteria for interstitial lung diseases. ${ }^{29-31}$ When available, chest $\mathrm{x}$-rays at the time of pneumonitis were also reviewed. Lung biopsy specimens obtained at the time of pneumonitis at MSKCC were reviewed by thoracic pathologists (C.L., N.R.) and phenotypically described.

\section{Outcomes Analysis}

For all patients treated with anti-PD-1/PD-L1 mAbs, associations between development of pneumonitis and treatment received (anti-PD-1 versus anti-PD-L1 mAb; monotherapy versus combination) and disease type (melanoma versus NSCLC stratified by monotherapy versus combination) were assessed by Fisher's exact test. In patients with pneumonitis, best objective response rates to anti-PD-1/PD-L1 mAbs were calculated with exact 95\% CIs. Associations among clinical or radiologic features of pneumonitis, treatment course, and outcomes from pneumonitis treatment were examined. In the radiologic assessment, agreement between individual radiologists was evaluated by Cohen $\kappa$-coefficient such that a score of 1 indicated complete agreement and 0 indicated no agreement other than what would be expected by chance. All statistical tests were two sided, and 5\% was set as the level of significance. Statistical analyses were performed with $\mathrm{R}$ version 3.1 .1 software (R Development Core Team), including the irr and Hmisc packages.

\section{RESULTS}

\section{Incidence of Pneumonitis}

Nine hundred fifteen patients received anti-PD-1/PD-L1 mAbs as monotherapy or in combination with anti-CTLA-4 mAb (Table 1). The overall incidence of pneumonitis was 5\% (43 of 915; 95\% CI, 3\% to $6 \%$ ) and was similar within institutional cohorts (MSKCC, 27 of 578 [5\%]; 95\% CI, 3\% to 7\%; MIA, 16 of 337 [5\%]; 95\% CI, 3\% to $8 \%$ ). The incidence of pneumonitis was greater in patients who received combination therapy than in those who received monotherapy (19 of 199 [10\%] $v 24$ of 716 [3\%], $P<.001$ ) and was not statistically different in those treated with anti-PD-1 compared with anti-PD-L1 mAb (monotherapy, 22 of 564 [4\%] $v$ two of 152 [1\%], $P=.13$; combination, 18 of 178 [10\%] $v$ one of $21[5 \%], P=.70)$.

\section{Patients With Pneumonitis}

Pneumonitis occurred in patients with metastatic melanoma (26 of 532 [5\%]) and NSCLC (nine of 209 [4\%]), hematologic malignancies (four of $35[11 \%]$ ), bladder carcinoma (one of 30 [3\%]), breast carcinoma (one of $14[7 \%]$ ), pancreatic carcinoma (one of $18[6 \%]$ ), and head and neck squamous carcinoma (one of 10 [10\%]; Table 2). Incidence was similar among patients with melanoma and NSCLC for monotherapy (15 of 417 [3.6\%] $v$ five of 152 [3.3\%], $P=1.0$ ) and combination therapy (11 of 115 [9.6\%] $v$ four of 57 [7.0\%], $P=.78$ ). Pneumonitis developed in both former/current smokers (24 of 43 [56\%]) and never smokers (19 of 43 [44\%]); the majority had not received prior chest radiation therapy (27 of 43 [63\%]). Pneumonitis occurred irrespective of line of therapy in which immunotherapy was received (first line, 32\%; second line, 40\%; third line or more, 28\%). Across all evaluable patients $(n=41)$, the best objective response to therapy was $61 \%$ (25 of $41 ; 95 \%$ CI, $45 \%$ to $76 \%$; Table 2 ). Among patients with melanoma, the response rate to monotherapy was $73 \%$ (11 of $15 ; 95 \%$ CI, $45 \%$ to $91 \%$ ) and to combination therapy, $73 \%$ (eight of $11 ; 95 \%$ CI, 39\% to $94 \%$ ).

\section{Clinical Features}

Median time to onset of pneumonitis was 2.8 months, with a wide range ( 9 days to 19.2 months; Fig 1). Onset tended to be 


\begin{tabular}{|c|c|c|}
\hline & MSKCC, No. (\%) & MIA, No. (\%) \\
\hline No. of patients & 578 & 337 \\
\hline \multicolumn{3}{|l|}{ Single agent $v$ combination } \\
\hline Monotherapy & $441(76)$ & $275(82)$ \\
\hline Combination & $137(24)$ & $62(18)$ \\
\hline \multicolumn{3}{|l|}{ PD-1 v PD-L1 } \\
\hline PD-1 & $405(70)$ & $337(100)$ \\
\hline PD-L1 & $173(30)$ & 0 \\
\hline \multicolumn{3}{|l|}{ Primary cancer type } \\
\hline Non-small-cell lung carcinoma & 209 & 0 \\
\hline Metastatic melanoma & 195 & 337 \\
\hline Renal cell carcinoma & 24 & 0 \\
\hline Hematologic malignancy & 35 & 0 \\
\hline Bladder carcinoma & 30 & 0 \\
\hline Pancreatic carcinoma & 18 & 0 \\
\hline Breast carcinoma & 14 & 0 \\
\hline Head and neck squamous carcinoma & 10 & 0 \\
\hline Sarcoma & 7 & 0 \\
\hline Colorectal carcinoma & 6 & 0 \\
\hline Gastroesophageal carcinoma & 12 & 0 \\
\hline Ovarian carcinoma & 7 & 0 \\
\hline Hepatocellular carcinoma & 4 & 0 \\
\hline Prostate carcinoma & 3 & 0 \\
\hline Anal carcinoma & 2 & 0 \\
\hline Small-cell lung carcinoma & 2 & 0 \\
\hline \multicolumn{3}{|l|}{ Pneumonitis } \\
\hline No & 551 (95) & 321 (95) \\
\hline Yes & $27(5)$ & $16(5)$ \\
\hline \multicolumn{3}{|c|}{$\begin{array}{l}\text { NOTE. Patients who received either an anti-PD-1 or an anti-PD-L1 monoclonal } \\
\text { antibody either as monotherapy or in combination with anti-CTLA-4 monoclonal } \\
\text { antibody. } \\
\text { Abbreviations: CTLA-4, cytotoxic T-cell lymphocyte-4; MIA, Melanoma Institute } \\
\text { of Australia; MSKCC, Memorial Sloan Kettering Cancer Center; PD-1, pro- } \\
\text { grammed death-1; PD-L1, programmed death ligand 1. }\end{array}$} \\
\hline
\end{tabular}

earlier in patients who received combination therapy than in those who received monotherapy (median, 2.7 months [range, 9 days to 6.9 months] $v 4.6$ months [range, 21 days to 19.2 months]; $P=0.02)$. Seventeen $(40 \%)$ patients experienced grade 1 pneumonitis, 14 (33\%) experienced grade 2, 10 (23\%) experienced grade 3 , one $(2 \%)$ experienced grade 4 , and one $(2 \%)$ experienced grade 5 ; no difference in distribution of severity between monotherapy and combination therapy was found (Fig 2).

The most common presenting symptoms of pneumonitis were dyspnea (23 of 43 [53\%]) and cough (15 of 43 [35\%]). Fever (five of $43[12 \%]$ ) and chest pain (three or 43 [7\%]) were less common. One third of patients were asymptomatic at the onset of pneumonitis (14 of 43 [33\%]). Three patients recorded as having grade 1 pneumonitis had symptoms on retrospective chart review, but grading was not changed retrospectively.

More than one half of patients with pneumonitis experienced additional immune-related toxicity (25 of 43 [58\%]), which included skin rash $(n=8)$; colitis $(n=6)$; hypophysitis, arthritis, and thyroiditis ( $\mathrm{n}=3 \mathrm{each}$ ); and hepatitis, esophagitis, duodenitis, hyperthyroidism, nephritis, myositis, vitiligo, pernicious anemia, and hemolytic anemia ( $\mathrm{n}=1$ each).

\section{Pneumonitis Management}

Most patients with grade 1 to 2 pneumonitis were managed as outpatients (25 of 31 [81\%]), whereas 19\% (six of 31 , all grade 2 ) were hospitalized. All grade 3 and higher cases $(n=12)$ required hospitalization. In patients with grade 1 pneumonitis, maximum treatment received was drug holding (15 of 17 [88\%]) or oral corticosteroids (two of 17 [12\%]; Table 3). All patients with grade 2 pneumonitis were treated initially with oral/intravenous corticosteroids $(n=14)$. All patients with grade 3 or higher pneumonitis received oral/intravenous corticosteroids initially $(n=12)$, five $(42 \%)$ of whom required additional immunosuppression (three with infliximab and two with both infliximab plus cyclophosphamide).

Among all patients who received corticosteroids (28 of 43 [65\%]), $61 \%$ (17 of 28 ) began with oral treatment, and 39\% (11 of 28 ) began with intravenous treatment. For most patients who began oral corticosteroids, this was the maximum immunosuppression used (14 of 17 [82\%]), with a median starting dose of prednisone of $50 \mathrm{mg}$ (range, 20 to $80 \mathrm{mg}$ ) and median duration of corticosteroid treatment of 68 days (range, 20 to 154 days).

\section{Clinical Outcomes and Mortality Associated With Pneumonitis}

Pneumonitis improved/resolved in $88 \%$ (37 of 43) of cases (Table 3), which included all grade 1 (17 of 17), 93\% (13 of 14; one patient lost to follow-up and outcome unknown) of grade 2, and $64 \%$ (seven of 12) of grade 3 and higher events.

Five $(12 \%)$ patients clinically worsened during treatment of pneumonitis. All had grade 3 and higher pneumonitis, were treated with additional immunosuppression beyond corticosteroids, and ultimately died. Although one patient's death was solely attributable to pneumonitis, the cause of clinical worsening and death was multifactorial in most cases. Three patients had infections associated with immunosuppression, and one patient had progressive cancer, which seemed to be the most proximal contributors to death.

The patient with grade 5 pneumonitis had initially presented with grade 2 pneumonitis after six doses of anti-PD-1 monotherapy for the treatment of metastatic NSCLC. Oral corticosteroids were initiated, with initial clinical and radiologic improvement. However, pneumonitis recurred during corticosteroid taper and did not improve with high-dose intravenous corticosteroids, infliximab, and cyclophosphamide, and the patient died.

Three patients died as a result of infection in the context of immunosuppression for pneumonitis. One patient received one dose of the anti-PD-1 plus anti-CTLA-4 mAb for melanoma and then was treated for grade 3 pneumonitis with a prolonged course of oral/intravenous corticosteroids over 2 months as well as infliximab. Although the pneumonitis initially seemed to improve, the patient developed pseudomonas pneumonia during corticosteroid treatment and subsequently died. A second patient received two doses of anti-PD-1 mAb for NSCLC and grade 3 pneumonitis developed, which was treated with methylprednisone and infliximab. The patient's condition was complicated by herpes simplex virus 1 sepsis, which resulted in death. A third patient with NSCLC received 38 doses of anti-PD-1 mAb before grade 3 pneumonitis developed that required long-term corticosteroids, infliximab, and cyclophosphamide treatment. The patient died, and on autopsy, fulminant necrotizing fungal pneumonia (mucormycosis) was identified and attributed as the cause of death; no residual cancer was identified. 
Table 2. Demographic Characteristics and Treatment and Response Data for Patients With Pneumonitis

\begin{tabular}{|c|c|}
\hline Clinical Feature & No. $(\%)$ \\
\hline \multicolumn{2}{|l|}{ Patient feature } \\
\hline Median age, years (range) & 67 (36-89) \\
\hline \multicolumn{2}{|l|}{ Smoking status } \\
\hline Current/former & $24(56)$ \\
\hline Never* & $19(44)$ \\
\hline \multicolumn{2}{|l|}{ Single agent $v$ combination therapy } \\
\hline Monotherapy & $24(56)$ \\
\hline Combination & $19(44)$ \\
\hline \multicolumn{2}{|l|}{ Underlying lung condition } \\
\hline None & $27(63)$ \\
\hline Asthma & $4(9)$ \\
\hline Bronchiectasis & $1(2)$ \\
\hline COPD & $1(2)$ \\
\hline Interstitial lung disease & $1(2)$ \\
\hline Pleural effusion & 2 (5) \\
\hline Pulmonary embolus & $4(9)$ \\
\hline Pleural effusion and pulmonary embolus & $1(2)$ \\
\hline Sleep apnea & 2 (5) \\
\hline \multicolumn{2}{|l|}{ Primary disease type } \\
\hline NSCLC & $9(20)$ \\
\hline Malignant melanoma & $26(60)$ \\
\hline Hematologic malignancy & $4(9)$ \\
\hline Bladder carcinoma & $1(2)$ \\
\hline Breast carcinoma & $1(2)$ \\
\hline Head and neck squamous cell carcinoma & $1(2)$ \\
\hline Pancreatic carcinoma & $1(2)$ \\
\hline \multicolumn{2}{|l|}{ Line of therapy } \\
\hline 1 & $14(33)$ \\
\hline 2 & $17(40)$ \\
\hline$\geq 3$ & $12(27)$ \\
\hline \multicolumn{2}{|l|}{ Prior chest radiation therapy } \\
\hline No & $27(63)$ \\
\hline Yes & $16(37)$ \\
\hline \multicolumn{2}{|l|}{ Prior immune checkpoint blockade } \\
\hline No & $32(74)$ \\
\hline Yes & $11(26)$ \\
\hline \multicolumn{2}{|l|}{ Anti-PD-1/PD-L1 treatment data } \\
\hline \multicolumn{2}{|l|}{ Single agent $v$ combination therapy } \\
\hline Combination & $19(44)$ \\
\hline Monotherapy & $24(56)$ \\
\hline \multicolumn{2}{|l|}{ PD-1 $v$ PD-L1 } \\
\hline PD-1 & $40(93)$ \\
\hline PD-L1 & $3(7)$ \\
\hline Median No. of doses (range) & $4(1-38)$ \\
\hline \multicolumn{2}{|l|}{ Best objective responset } \\
\hline CR/PR & 25 \\
\hline PD & 2 \\
\hline SD & 14 \\
\hline
\end{tabular}

Abbreviations: $C O P D$, chronic obstructive pulmonary disease; $C R$, complete response; NSCLC, non-small-cell lung carcinoma; PD, progressive disease; PD-1, programmed death-1; PD-L1, programmed death ligand 1; PR, partial response; $\mathrm{SD}$, stable disease.

* Never smokers smoked $<100$ cigarettes in lifetime.

†Assessed with Response Evaluation Criteria in Solid Tumors (RECIST) 1.1 $(n=27)$, Immune-Related Response Criteria $(n=10)$, Cheson criteria $(n=2)$, International Myeloma Working Group Criteria $(n=1)$, and modified Severity Weighted Assessment Tool $(n=1)$; two patients not assessed.

\section{Recurrent Pneumonitis: With or Without T-Cell Checkpoint Rechallenge}

Eleven patients experienced recurrent pneumonitis during drug holding/corticosteroid therapy after initial clinical improvement (Appendix Table A1, online only). Of these patients in whom recurrence occurred without drug rechallenge, eight experienced resolution/improvement with further management and three worsened and died despite immunosuppression.

Twelve patients underwent rechallenge with immunotherapy after an initial pneumonitis event (nine grade 1 and three grade 2; nine treated with drug holding only and three treated with corticosteroids for initial event; Appendix Table A2, online only). All rechallenged cases occurred after complete clinical resolution of pneumonitis. Nine patients did not experience a second pneumonitis event on rechallenge (eight grade 1 and one grade 2), whereas three experienced recurrent pneumonitis after rechallenge of whom one patient initially had grade 1 pneumonitis treated with drug hold only, and had recurrent pneumonitis that was again grade 1 and resolved with drug holding. The other two patients had grade 2 pneumonitis initially, were treated with corticosteroids, and had recurrent grade 2 pneumonitis that again resolved with oral corticosteroids.

\section{Radiologic Features}

Radiologic and clinical outcomes of pneumonitis were aligned in all patients who experienced clinical improvement/ resolution (37 of 37), and four of five patients who experienced clinical worsening of their pneumonitis. Serial chest CT scans were available for all MSKCC patients. Radiologic features of pneumonitis were classified into five subtypes (Fig 3): cryptogenic organizing pneumonia (COP) like (five of 27 [19\%]), ground glass opacities (GGO; 10 of 27 [37\%]), interstitial (two of $27[7 \%]$ ), hypersensitivity (six of $27[22 \%]$ ), and pneumonitis not otherwise specified (four of 27 [15\%]). Radiologic severity at the time of pneumonitis was classified as mild (15 of 27 [56\%]), moderate (six of 27 [22\%]), or severe (six of 27 [22\%]; Appendix Fig A1, online only). Cohen $\kappa$-coefficients were 0.66 for radiologic subtype and 0.88 for radiologic severity grading, respectively. Radiologic subtypes were consistent throughout a patient's clinical course, except in two cases where COP-like pneumonitis evolved into a severe GGO type, and where GGO type developed additional interstitial appearances. COP-like appearance was more common among patients with NSCLC than among patients with other cancers (four of nine $v$ one of 18 , $P=.03)$. In addition, patients with the COP-like subtype were more likely to require treatment of pneumonitis (beyond drug hold) than those with other radiologic subtypes (five of five $v 11$ of 22, $P=.06$ ). Chest $\mathrm{x}$-rays obtained at the time of pneumonitis $(n=9)$ demonstrated possible pneumonitis in $67 \%$ of cases (six of nine), possible progressive cancer in $11 \%$ (one of nine), and no new radiographic abnormality in $22 \%$ (two of nine).

\section{Pathologic Features}

Eleven of $27(41 \%)$ patients at MSKCC underwent lung biopsy at the time of pneumonitis (eight bronchoscopic, two core biopsies, one wedge resection; Appendix Table A3, online only). Histopathologic findings were cellular interstitial pneumonitis (four of 11; Appendix Fig A2A, online only), organizing pneumonia (three of 11; Appendix Fig A2B), diffuse alveolar damage (one of 11; Appendix Fig A2C), and no abnormalities identified (three of 11). The interstitial inflammatory infiltrate included poorly formed granulomas in 


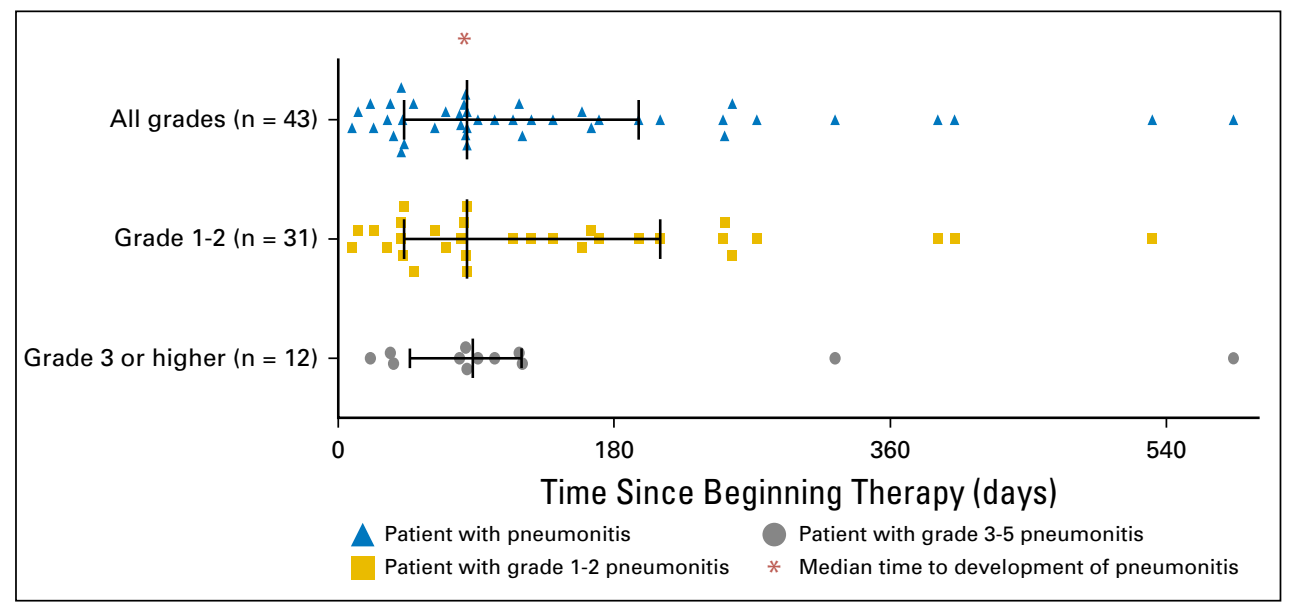

Fig 1. Time from first dose of antiprogrammed death-1/programmed death ligand 1 therapy to date of pneumonitis event stratified by grade, with interquartile range and median values shown.

three cases (Appendix Fig A2D) and eosinophils in two cases (Appendix Fig A2E).

\section{Associations Between Clinical Features and Pneumonitis Outcomes}

Worsening clinical outcomes with pneumonitis were more frequent in current versus former smokers (five of $23 v$ zero of 19, $P=.053)$ and those with underlying lung conditions versus no lung conditions (four of $15 v$ one of 27, $P=.047$; Appendix Table A4, online only). Forced expiratory volume in 1 second and diffusing capacity of lung for carbon monoxide adjusted for hemoglobin were completed in a subset of patients at the time of pneumonitis
(16 of 43 and 12 of 43, respectively); no associations between these parameters and clinical outcomes were seen.

\section{DISCUSSION}

We describe the first large series of pneumonitis to our knowledge associated with anti-PD-1/PD-L1 mAbs in patients with advanced cancers and comprehensively characterize the clinical, radiologic, and pathologic features, and management of this toxicity. Anygrade pneumonitis developed in approximately $5 \%$ of patients treated with anti-PD-1/PD-L1 mAbs, and grade 3 and higher pneumonitis developed in $1 \%$. Pneumonitis was more common in

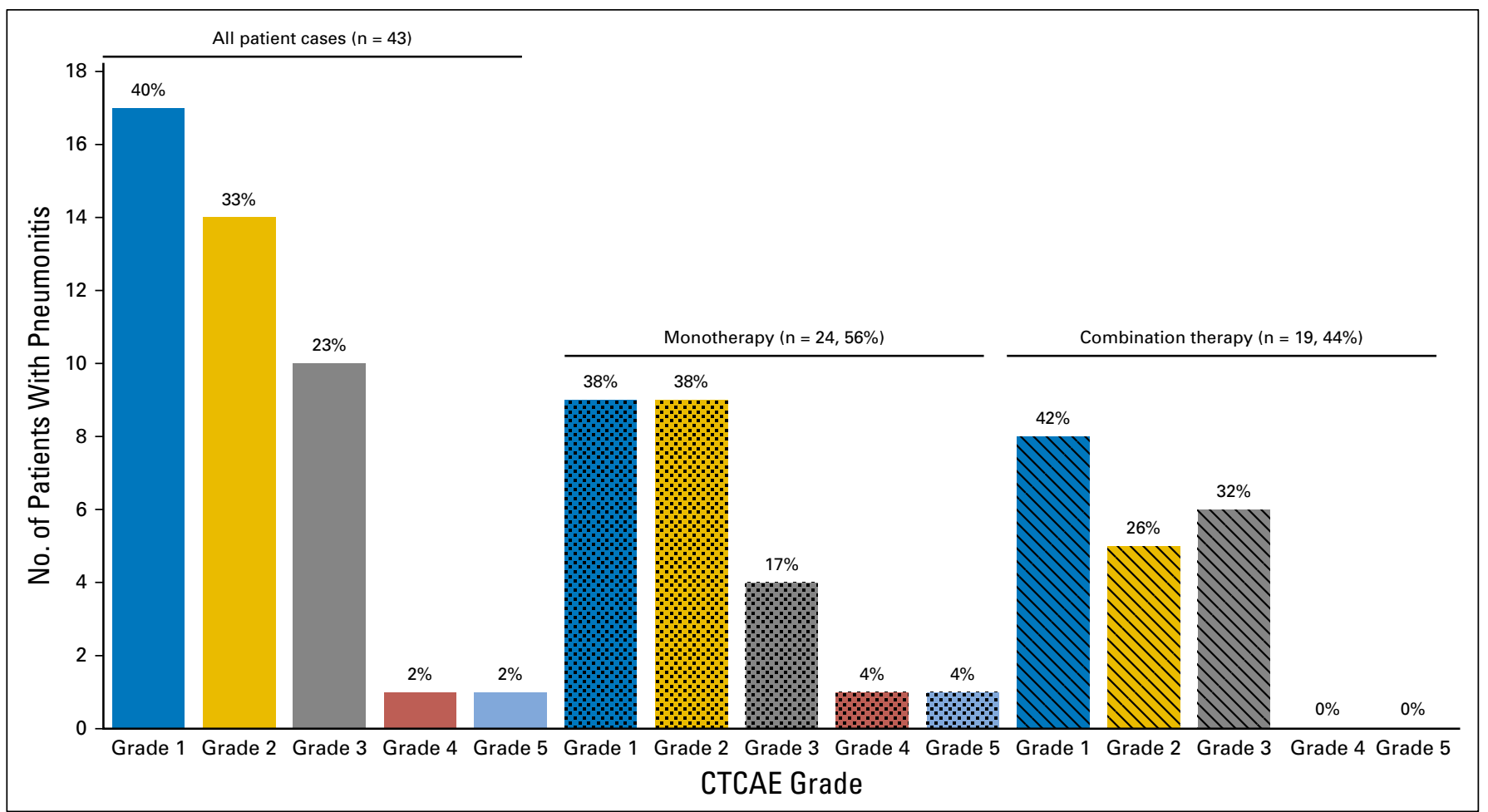

Fig 2. Patients in whom pneumonitis developed stratified by highest Common Terminology Criteria for Adverse Events (version 4.0; CTCAE) grade, including whether

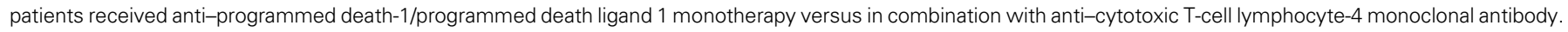




\begin{tabular}{|c|c|c|c|c|c|}
\hline \multirow[b]{2}{*}{ Highest CTCAE Grade } & \multicolumn{5}{|c|}{ Highest Treatment Required for Pneumonitis Management, No. (\%) } \\
\hline & Treatment Hold & Oral Corticosteroids & Intravenous Corticosteroids & $\begin{array}{c}\text { Additional } \\
\text { Immunosuppression* }\end{array}$ & Total \\
\hline 1 & $15(83)$ & $2(12)$ & $0(0)$ & $0(0)$ & 17 \\
\hline 2 & $0(0)$ & $10(71)$ & $4(29)$ & $0(0)$ & 14 \\
\hline 3 & $0(0)$ & $2(20)$ & $4(40)$ & $4(40)$ & 10 \\
\hline 4 & $0(0)$ & $0(0)$ & $1(100)$ & $0(0)$ & 1 \\
\hline 5 & $0(0)$ & $0(0)$ & $0(0)$ & $1(100)$ & 1 \\
\hline \multirow[t]{3}{*}{ Total } & 15 & 14 & 9 & 5 & 43 \\
\hline & \multicolumn{5}{|c|}{ Clinical Outcomes of Pneumonitis Management, No. (\%) } \\
\hline & $\begin{array}{c}\text { Completely } \\
\text { Resolved }\end{array}$ & Improved & Worsened & Unknown & Total \\
\hline 1 & $17(100)$ & $0(0)$ & $0(0)$ & $0(0)$ & 17 \\
\hline 2 & $10(71)$ & $3(21)$ & $0(0)$ & $1(8)$ & 14 \\
\hline 3 & $4(40)$ & $2(20)$ & $4(40)$ & $0(0)$ & 10 \\
\hline 4 & $1(100)$ & $0(0)$ & $0(0)$ & $0(0)$ & 1 \\
\hline 5 & $0(0)$ & $0(0)$ & $1(100)$ & $0(0)$ & 1 \\
\hline Total & 32 & 5 & 5 & 1 & 43 \\
\hline
\end{tabular}

Abbreviation: CTCAE, Common Terminology Criteria for Adverse Events (version 4).

*Additional immunosuppression: Three patients received infliximab alone (all grade 3 ), and two patients received both infliximab and cyclophosphamide (one grade 3 and one grade 5).

patients treated with anti-PD-1/PD-L1 mAbs plus anti-CTLA-4 $\mathrm{mAb}$ compared with anti-PD-1/PD-L1 monotherapy. Rates of pneumonitis with anti-PD-1 versus anti-PD-L1 mAb in this series were not statistically different; however, larger data sets that include meta-analyses across tumor types are needed to determine conclusively whether a difference exists. Most cases of pneumonitis were mild, which is reassuring, but with the increasing use of anti-PD-1/PD-L1 mAbs in many disease settings, the absolute burden of pneumonitis undoubtedly will rise.

Most patients with pneumonitis were symptomatic at presentation, with one third of cases identified incidentally by imaging. Because timing of pneumonitis onset varied widely, constant vigilance for the signs and symptoms of this toxicity is required.

The majority of patients with pneumonitis in this study were also responders to immunotherapy, although they also had a variety of diseases, treatments, and systems of assessment. Additionally, there may be confounding between increased time on therapy and the association between both risk of pneumonitis and likelihood of benefit from immunotherapy. Nevertheless, it is intriguing to consider a possible mechanistic association between benefit and toxicity with anti-PD-1/PD-L1 agents.

We also describe the varied clinical, radiologic, and pathologic features of anti-PD-1/PD-L1 pneumonitis. Unlike bleomycininduced pneumonitis, which is characterized by specific radiologic appearances ${ }^{23}$ and changes in diffusing capacity of lung for carbon monoxide, ${ }^{32}$ we did not identify any pathognomonic radiographic or pathologic features of anti-PD-1/PD-L1 pneumonitis. To provide a common language for this toxicity, we describe distinct radiologic phenotypes by $\mathrm{CT}^{26,33}$ and found acceptable concordance between independent radiologic reviewers. Because radiology review was only performed in clinically determined pneumonitis cases, the real-world interobserver concordance of radiologic assessments may be lower. Of note, chest $\mathrm{x}$-ray did not detect a new radiographic abnormality in nearly one quarter of pneumonitis cases, which suggests that it may be an inadequate tool for evaluating suspected pneumonitis.
Clinically, nearly all cases of pneumonitis improved/resolved with drug holding and/or immunosuppression. However, some cases worsened and were fatal. In this series, worsening cases were restricted to current and former smokers and were more common in patients with underlying lung conditions; such patients may require particularly careful management. Among patients in whom pneumonitis improved/resolved, 12 (all with grade 1 to 2) underwent rechallenge with anti-PD-1/PD-L1 mAbs, and recurrent pneumonitis occurred in three (25\%). This suggests that in mild cases, one may cautiously resume therapy after pneumonitis has improved/resolved and after careful discussion with the patient.

Although most instances of pneumonitis were not severe, five deaths occurred, and in three cases, infection from prolonged immunosuppression contributed to death. No patient who received immunosuppression beyond corticosteroids (infliximab with or without cyclophosphamide) recovered from pneumonitis. Improvement is needed in the choice, dose, and duration of therapies for pneumonitis with consideration of the role of antimicrobial prophylaxis in the context of prolonged immunosuppression.

Drug-induced pneumonitis remains a diagnosis of exclusion and requires consideration of competing diagnoses, including infection and malignant lung infiltration. Diagnostic bronchoscopy with lung biopsy may play an important role in excluding competing diagnoses. We attempted to exclude cases with alternative etiologies and evidence of pulmonary infection or infiltrative cancer. However, the excluded cases may have represented true pneumonitis or mixed presentation. In addition some cases of pneumonitis may not have been detected radiologically, so the true incidence of pneumonitis may be higher than that described here. This series largely comprised patients with melanoma and NSCLC; a larger series that investigates pneumonitis as a result of anti-PD-1/PD-L1 mAbs in other malignancies are needed. Finally, this series describes the features of pneumonitis, but did not seek to identify risk factors for its development, which remains an open question for future investigation. 


\begin{tabular}{|c|c|c|}
\hline Radiologic Subtypes & Representative Image & Description \\
\hline $\begin{array}{c}\text { Cryptogenic } \\
\text { organizing } \\
\text { pneumonia-like } \\
(\mathrm{n}=5,19 \%)\end{array}$ & & $\begin{array}{l}\text { Discrete patchy or confluent } \\
\text { consolidation with or without air } \\
\text { bronchograms } \\
\text { Predominantly peripheral or } \\
\text { subpleural distribution }\end{array}$ \\
\hline $\begin{array}{c}\text { Ground glass } \\
\text { opacities } \\
(n=10,37 \%)\end{array}$ & & $\begin{array}{l}\text { Discrete focal areas of increased } \\
\text { attenuation } \\
\text { Preserved bronchovascular } \\
\text { markings }\end{array}$ \\
\hline $\begin{array}{l}\text { Interstitial } \\
(n=6,22 \%)\end{array}$ & & $\begin{array}{l}\text { Increased interstitial markings, } \\
\text { interlobular septal thickening } \\
\text { Peribronchovascular infiltration, } \\
\text { subpleural reticulation } \\
\text { Honeycomb pattern in severe } \\
\text { patient cases }\end{array}$ \\
\hline $\begin{array}{l}\text { Hypersensitivity } \\
\qquad(\mathrm{n}=2,7 \%)\end{array}$ & & $\begin{array}{l}\text { Centrilobular nodules } \\
\text { Bronchiolitis-like appearance } \\
\text { Tree-in-bud micronodularity }\end{array}$ \\
\hline $\begin{array}{l}\text { Pneumonitis } \\
\text { not otherwise } \\
\text { specified } \\
(n=4,15 \%)\end{array}$ & & $\begin{array}{l}\text { Mixture of nodular and other } \\
\text { subtypes } \\
\text { Not clearly fitting into other } \\
\text { subtype classifications }\end{array}$ \\
\hline
\end{tabular}

Fig 3. Radiologic features of pneumonitis associated with anti-programmed death-1/programmed death ligand 1 therapy stratified into five distinct phenotypes.
This study fills an important gap in the literature because the only published data on anti-PD-1/PD-L1 pneumonitis are from two small case reports ${ }^{34,35}$ and two larger case series reported at ASCO 2016. ${ }^{36,37}$ Collectively, these reports affirm the variable timing of onset and potential for recurrent pneumonitis during pneumonitis management. Although these studies cannot make firm recommendations about optimal pneumonitis management, grade 1 pneumonitis seems reasonable to treat with drug holding alone, with close clinical and radiologic follow-up (2 to 4 weeks) for resolution/ improvement. If symptoms arise or no radiologic improvement is seen, corticosteroids are appropriate. Grade 2 and higher pneumonitis should be treated with corticosteroids in addition to drug holding, with continued close clinical and radiologic follow-up. Patients in whom worsening pneumonitis develops can be resistant to traditional immunosuppression and may benefit from studies of early additional or new/alternative immunosuppression.

In summary, pneumonitis is an uncommon but potentially serious toxicity that occurs in $5 \%$ of patients who receive antiPD-1/PD-L1 mAbs. Treating physicians should be aware of its diverse clinical, radiologic, and pathologic features and that it may develop at any time during a patient's treatment course. Most cases are mild and managed successfully with favorable outcomes. However, worsening pneumonitis may develop in a subset of patients despite additional immunosuppression, and they may suffer from the immunosuppressive consequences of pneumonitis treatment. Improvements in the treatment and understanding of the biology of pneumonitis are needed to optimize management.

\section{AUTHORS' DISCLOSURES OF POTENTIAL CONFLICTS OF INTEREST}

Disclosures provided by the authors are available with this article at jco.org.

\section{AUTHOR CONTRIBUTIONS}

Conception and design: Jarushka Naidoo, Tunc Iyriboz, Jane Cunningham, Charles Leduc, Georgina V. Long, Matthew D. Hellmann

Provision of study materials or patients: Jamie E. Chaft, Neil H. Segal, Margaret K. Callahan, Alexander M. Lesokhin, Jonathan Rosenberg, Martin H. Voss, Charles M. Rudin, Ruth-Ann Gordon, Matteo S. Carlino, Jedd D. Wolchok, Michael A. Postow, Georgina V. Long, Matthew D. Hellmann

Collection and assembly of data: Jarushka Naidoo, Xuan Wang, Tunc Iyriboz, Darragh Halpenny, Jane Cunningham, Jamie E. Chaft, Neil H. Segal, Margaret K. Callahan, Alexander M. Lesokhin, Jonathan Rosenberg, Martin H. Voss, Charles M. Rudin, Hira Rizvi, Xue Hou, Katherine Rodriguez, Melanie Albano, Ruth-Ann Gordon, Charles Leduc, Natasha Rekhtman, Alexander M. Menzies, Alexander D. Guminski, Matteo S. Carlino, Benjamin Y. Kong, Georgina V. Long, Matthew D. Hellmann 
Data analysis and interpretation: Jarushka Naidoo, Xuan Wang, Kaitlin M. Woo, Darragh Halpenny, Jane Cunningham, Jamie E. Chaft, Neil H. Segal, Margaret K. Callahan, Alexander M. Lesokhin, Jonathan Rosenberg, Martin H. Voss, Charles M. Rudin, Hira Rizvi, Katherine Rodriguez, Melanie Albano, Ruth-Ann Gordon, Charles Leduc, Natasha Rekhtman, Bianca Harris, Alexander M. Menzies,
Alexander D. Guminski, Matteo S. Carlino, Benjamin Y. Kong, Jedd D. Wolchok, Michael A. Postow, Georgina V. Long, Matthew D.

Hellmann

Manuscript writing: All authors

Final approval of manuscript: All authors

Accountable for all aspects of the work: All authors

\section{REFERENCES}

1. Weber JS, D'Angelo SP, Minor D, et al: Nivolumab versus chemotherapy in patients with advanced melanoma who progressed after anti-CTLA-4 treatment (CheckMate 037): A randomised, controlled, open-label, phase 3 trial. Lancet Oncol 16:375-384, 2015

2. Robert C, Ribas A, Wolchok JD, et al: Antiprogrammed-death-receptor-1 treatment with pembrolizumab in ipilimumab-refractory advanced melanoma: A randomised dose-comparison cohort of a phase 1 trial. Lancet 384:1109-1117, 2014

3. Brahmer J, Reckamp KL, Baas $P$, et al: Nivolumab versus docetaxel in advanced squamous-cell nonsmall-cell lung cancer. N Engl J Med 373:123-135, 2015

4. Borghaei H, Paz-Ares L, Horn L, et al: Nivolumab versus docetaxel in advanced nonsquamous non-small-cell lung cancer. N Engl J Med 373:1627-1639, 2015

5. Garon EB, Rizvi NA, Hui R, et al: Pembrolizumab for the treatment of non-small-cell lung cancer. N Engl J Med 372:2018-2028, 2015

6. Herbst RS, Baas P, Kim DW, et al: Pembrolizumab versus docetaxel for previously treated, PD-L1-positive, advanced non-small-cell lung cancer (KEYNOTE-010): A randomised controlled trial. Lancet, 387:1540-1550, 2015

7. Motzer RJ, Escudier B, McDermott DF, et al: Nivolumab versus everolimus in advanced renal-cell carcinoma. N Engl J Med 373:1803-1813, 2015

8. Ansell SM, Lesokhin AM, Borrello I, et al: PD-1 blockade with nivolumab in relapsed or refractory Hodgkin's lymphoma. N Engl J Med 372:311-319, 2015

9. Rosenberg JE, Hoffman-Censits J, Powles T, et al: Atezolizumab in patients with locally advanced and metastatic urothelial carcinoma who have progressed following treatment with platinum-based chemotherapy: A single-arm, multicentre, phase 2 trial. Lancet 387:1909-1920, 2016

10. Larkin J, Chiarion-Sileni V, Gonzalez R, et al: Combined nivolumab and ipilimumab or monotherapy in untreated melanoma. N Engl J Med 373:23-34, 2015

11. Le DT, Uram JN, Wang $H$, et al: PD-1 blockade in tumors with mismatch-repair deficiency. $\mathrm{N}$ Engl J Med 372:2509-2520, 2015

12. Herbst RS, Soria JC, Kowanetz M, et al: Predictive correlates of response to the anti-PD-L1 antibody MPDL3280A in cancer patients. Nature 515: 563-567, 2014
13. Gillison $M L$, Blumenschein $G$, Fayette $J$, et al: Nivolumab (nivo) vs investigator's choice (IC) for recurrent or metastatic $(\mathrm{R} / \mathrm{M})$ head and neck squamous cell carcinoma (HNSCC): CheckMate-141. Presented at the American Association for Cancer Research Annual Meeting, New Orleans, LA, April 16-20, 2016

14. Antonia S, Goldberg SB, Balmanoukian A, et al: Safety and antitumour activity of durvalumab plus tremelimumab in non-small cell lung cancer: A multicentre, phase 1b study. Lancet Oncol 17: 299-308, 2016

15. Rizvi NA, Gettinger SN, Goldman JW, et al: Safety and efficacy of first-line nivolumab (NIVO; antiprogrammed death-1 [PD-1]) and ipilimumab in nonsmall cell lung cancer (NSCLC). Presented at the International Association for the Study of Lung Cancer Annual Meeting, Denver, CO, September 6-9, 2015

16. Weber JS, Yang JC, Atkins MB, et al: Toxicities of immunotherapy for the practitioner. J Clin Oncol 33:2092-2099, 2015

17. Postow MA: Managing immune checkpointblocking antibody side effects. Am Soc Clin Oncol Educ Book 35:76-83, 2015

18. Topalian SL, Hodi FS, Brahmer JR, et al: Safety, activity, and immune correlates of anti-PD-1 antibody in cancer. N Engl J Med 366:2443-2454, 2012

19. Disayabutr S, Calfee CS, Collard HR, et al: Interstitial lung diseases in the hospitalized patient. BMC Med 13:245, 2015

20. Naidoo J, Page DB, Li BT, et al: Toxicities of the anti-PD-1 and anti-PD-L1 immune checkpoint antibodies. Ann Oncol 26:2375-2391, 2015

21. Genestreti G, Di Battista $M$, Trisolini R, et al: $A$ commentary on interstitial pneumonitis induced by docetaxel: Clinical cases and systematic review of the literature. Tumori 101:e92-e95, 2015

22. Poole BB, Hamilton LA, Brockman MM, et al: Interstitial pneumonitis from treatment with gemcitabine. Hosp Pharm 49:847-850, 2014

23. Comis RL: Bleomycin pulmonary toxicity: current status and future directions. Semin Oncol 19:64-70, 1992 (suppl 5)

24. Ando M, Okamoto I, Yamamoto $N$, et al: Predictive factors for interstitial lung disease, antitumor response, and survival in non-small-cell lung cancer patients treated with gefitinib. J Clin Oncol 24 2549-2556, 2006
25. Liu V, White DA, Zakowski MF, et al: Pulmonary toxicity associated with erlotinib. Chest 132: 1042-1044, 2007

26. White DA, Camus $P$, Endo $M$, et al: Noninfectious pneumonitis after everolimus therapy for advanced renal cell carcinoma. Am J Respir Crit Care Med 182:396-403, 2010

27. Bradley J, Movsas B: Radiation pneumonitis and esophagitis in thoracic irradiation. Cancer Treat Res 128:43-64, 2006

28. Weshler $Z$, Breuer $R$, Or $R$, et al: Interstitial pneumonitis after total body irradiation: Effect of partial lung shielding. Br J Haematol 74:61-64, 1990

29. Palmucci S, Roccasalva F, Puglisi $S$, et al: Clinical and radiological features of idiopathic interstitial pneumonias (IIPS): A pictorial review. Insights Imaging 5:347-364, 2014

30. Johkoh T, Fukuoka J, Tanaka T: Rare idiopathic intestinal pneumonias (IIPS) and histologic patterns in new ATS/ERS multidisciplinary classification of the IIPs. Eur J Radiol 84:542-546, 2015

31. Kadoch MA, Cham MD, Beasley MB, et al: Idiopathic interstitial pneumonias: A radiology-pathology correlation based on the revised 2013 American Thoracic Society-European Respiratory Society classification system. Curr Probl Diagn Radiol 44:15-25, 2015

32. Comis RL: Detecting bleomycin pulmonary toxicity: A continued conundrum. J Clin Oncol 8: 765-767, 1990

33. Endo $M$, Johkoh $T$, Kimura $K$, et al: Imaging of gefitinib-related interstitial lung disease: Multiinstitutional analysis by the West Japan Thoracic Oncology Group. Lung Cancer 52:135-140, 2006

34. Nishino M, Sholl LM, Hodi FS, et al: Anti-PD-1related pneumonitis during cancer immunotherapy. N Engl J Med 373:288-290, 2015

35. Nishino M, Chambers ES, Chong CR, et al: AntiPD-1 inhibitor-related pneumonitis in non-small cell lung cancer. Cancer Immunol Res 4:289-293, 2016

36. Nishino M, Ramaiya NH, Awad MM, et al: PD-1 inhibitor-related pneumonitis in advanced cancer patients. Presented at the American Society of Clinical Oncology Annual Meeting, Chicago, IL, June 3-7, 2016

37. Gettinger SN, Zhang $X$, Homer $R$, et al: Pneumonitis in non-small cell lung cancer (NSCLC) patients treated with programmed death 1 (PD1) axis inhibitors. Presented at the American Society of Clinical Oncology Annual Meeting, Chicago, IL, June 3-7, 2016

\section{Affiliations}

Jarushka Naidoo, Kaitlin M. Woo, Tunc Iyriboz, Darragh Halpenny, Jane Cunningham, Jamie E. Chaft, Neil H. Segal, Margaret K. Callahan, Alexander M. Lesokhin, Jonathan Rosenberg, Martin H. Voss, Charles M. Rudin, Hira Rizvi, Xue Hou, Katherine Rodriguez, Melanie Albano, Ruth-Ann Gordon, Charles Leduc, Natasha Rekhtman, Bianca Harris, Jedd D. Wolchok, Michael A. Postow, and Matthew D. Hellmann, Memorial Sloan Kettering Cancer Center; Jamie E. Chaft, Neil H. Segal, Margaret K. Callahan, Alexander M. Lesokhin, Jonathan Rosenberg, Martin H. Voss, Charles M. Rudin, Jedd D. Wolchok, Michael A. Postow, and Matthew D. Hellmann, Weill Cornell Medical College, New York, NY; Jarushka Naidoo, Sidney Kimmel Cancer Center at Johns Hopkins University, Baltimore, MD; Xuan Wang, Peking University Cancer Hospital and Institute, Beijing; Xue Hou, Sun Yat-sen University Cancer Center, Guangdong Province, People’s Republic of China; Xuan Wang, Matteo S. Carlino, Benjamin Y. Kong, and Georgina V. Long, The University of Sydney; Alexander M. Menzies and Alexander D. Guminski, Royal North Shore and Mater Hospital; and Matteo S. Carlino and Benjamin Y. Kong, Westmead and Blacktown Hospitals, Sydney, Australia. 


\section{Support}

Supported by Memorial Sloan Kettering Cancer Center Support Grant/Core Grant No. P30 CA008748.

\section{Prior Presentation}

Presented in part at the European Cancer Congress 2015, Vienna, Austria, September 25-29 2015.

\section{Help Caregivers Learn About the Importance of Their Role in Cancer Care}

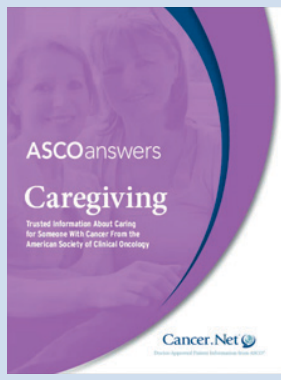

Cancer.Net offers a variety of tools and resources for caregivers, including the ASCO Answers:

Caregiving Guide. Designed to help caregivers learn more about supporting someone with cancer, this guide offers caregivers advice for talking with family and the health care team, convenient symptom and medication trackers, and more. Explore additional resources for caregivers at Cancer. Net/Caregiving. Order booklets for your practice. Free domestic shipping on all patient information resources and ASCO members save $20 \%$.

\section{ASC(9)}

American Society of Clinical Oncology 
Pneumonitis in Patients Treated With Anti-Programmed Death-1/Programmed Death Ligand 1 Therapy

The following represents disclosure information provided by authors of this manuscript. All relationships are considered compensated. Relationships are self-held unless noted. I = Immediate Family Member, Inst = My Institution. Relationships may not relate to the subject matter of this manuscript. For more information about ASCO's conflict of interest policy, please refer to www.asco.org/rwc or ascopubs.org/jco/site/ifc.

\section{Jarushka Naidoo}

Honoraria: Bristol-Myers Squibb, AstraZeneca

Consulting or Advisory Role: Bristol-Myers Squibb, AstraZeneca

Travel, Accommodations, Expenses: AstraZeneca, Bristol-Myers Squibb

\section{Xuan Wang}

No relationship to disclose

Kaitlin M. Woo

No relationship to disclose

Tunc Iyriboz

No relationship to disclose

Darragh Halpenny

No relationship to disclose

Jane Cunningham

No relationship to disclose

Jamie E. Chaft

Honoraria: DAVA Oncology

Consulting or Advisory Role: Myriad Genetics, Biodesix, Genentech, Roche, Clovis Oncology, AstraZeneca, MedImmune

Research Funding: Genentech (Inst), Roche (Inst), Bristol-Myers Squibb (Inst), AstraZeneca (Inst), MedImmune (Inst)

Neil H. Segal

Honoraria: MedImmune

Consulting or Advisory Role: Bristol-Myers Squibb, Pfizer, AstraZeneca, MedImmune, MacroGenics, Imugene, Roche, Genentech, Kyocera, Amgen, Calithera Biosciences

Research Funding: MedImmune, Bristol-Myers Squibb, Pfizer, Roche, Genentech, Merck

\section{Margaret K. Callahan}

Employment: Bristol-Myers Squibb (I), Celgene (I)

Consulting or Advisory Role: AstraZeneca

Research Funding: Bristol-Myers Squibb (Inst)

\section{Alexander M. Lesokhin}

Honoraria: Bristol-Myers Squibb, Janssen Pharmaceuticals, Gilead Sciences (I), Novartis

Consulting or Advisory Role: Bristol-Myers Squibb, Foundation Medicine (Inst), Janssen Pharmaceuticals, Novartis

Research Funding: Bristol-Myers Squibb (Inst), Janssen Pharmaceuticals (Inst), Genentech (Inst), Roche (Inst)

Patents, Royalties, Other Intellectual Property: Serametrix (Inst)

Jonathan Rosenberg

Stock or Other Ownership: Merck, Illumina

Honoraria: UpToDate

Consulting or Advisory Role: Boehringer Ingelheim, Bristol-Myers Squibb, Dendreon, Janssen Pharmaceuticals, Johnson \& Johnson, OncoGenex Pharmaceuticals, Onyx Pharmaceuticals, Eli Lilly, Merck, Agensys, Roche, Genentech, Sanofi

Research Funding: Genentech (Inst), OncoGenex Pharmaceuticals (Inst), Agensys (Inst), Mirati Therapeutics (Inst), Novartis (Inst)

Patents, Royalties, Other Intellectual Property: ERCC2-predicting cisplatin sensitivity

Travel, Accommodations, Expenses: Genentech, Roche
Martin H. Voss

Honoraria: Novartis

Consulting or Advisory Role: Novartis, Calithera Biosciences, Natera, GlaxoSmithKline, Exelixis

Research Funding: Pfizer, Bristol-Myers Squibb, Genentech, Roche Travel, Accommodations, Expenses: Novartis, Takeda Pharmaceuticals

Charles M. Rudin

Consulting or Advisory Role: Novartis, Bristol-Myers Squibb, Medivation

Hira Rizvi

No relationship to disclose

Xue Hou

No relationship to disclose

Katherine Rodriguez

No relationship to disclose

Melanie Albano

No relationship to disclose

Ruth-Ann Gordon

Consulting or Advisory Role: AstraZeneca

Charles Leduc

No relationship to disclose

Natasha Rekhtman

No relationship to disclose

Bianca Harris

No relationship to disclose

Alexander M. Menzies

Honoraria: Bristol-Myers Squibb, Novartis

Consulting or Advisory Role: MSD, Chugai Pharmaceutical

Travel, Accommodations, Expenses: Bristol-Myers Squibb

Alexander D. Guminski

Consulting or Advisory Role: Bristol-Myers Squibb, Novartis, Merck

Travel, Accommodations, Expenses: Bristol-Myers Squibb, Astellas

Pharma, Novartis, Merck

Matteo S. Carlino

Honoraria: Novartis, Merck Sharp \& Dohme, Bristol-Myers Squibb Consulting or Advisory Role: Novartis, Bristol-Myers Squibb, Merck Sharp \& Dohme, Amgen

Benjamin Y. Kong

No relationship to disclose

Jedd D. Wolchok

Stock or Other Ownership: Potenza Therapeutics, Vesuvius Pharmaceuticals

Consulting or Advisory Role: Bristol-Myers Squibb, Merck, MedImmune, ZIOPHARM Oncology, Polynoma, Polaris Pharmaceuticals, Jounce Therapeutics, Genentech

Research Funding: Bristol-Myers Squibb (Inst), MedImmune (Inst), GlaxoSmithKline (Inst), Merck (Inst)

Patents, Royalties, Other Intellectual Property: Coinventor on an issued patent for DNA vaccines for the treatment of cancer in companion animals Travel, Accommodations, Expenses: Bristol-Myers Squibb 
Michael A. Postow

Honoraria: Bristol-Myers Squibb, Merck

Consulting or Advisory Role: Amgen, Bristol-Myers Squibb

Research Funding: Bristol-Myers Squibb (Inst)

Travel, Accommodations, Expenses: Bristol-Myers Squibb

Georgina V. Long

Honoraria: Bristol-Myers Squibb, Merck, Roche, Genentech

Consulting or Advisory Role: Bristol-Myers Squibb, Roche, Genentech, Amgen, Merck, Provectus Pharmaceuticals, Novartis
Matthew D. Hellmann

Consulting or Advisory Role: Third Rock Ventures, Bristol-Myers Squibb, Merck, Genentech, Alexion Pharmaceuticals, Inovio Biomedical, AstraZeneca, MedImmune

Research Funding: Bristol-Myers Squibb 


\section{Appendix}

\begin{tabular}{|c|c|c|c|c|c|c|}
\hline \multicolumn{3}{|c|}{ Highest CTCAE Grade } & & \multicolumn{3}{|c|}{$\begin{array}{l}\text { No. of Patients With Recurrent Pneumonitis Without } \\
\text { Rechallenge }(n=11)\end{array}$} \\
\hline \multicolumn{3}{|l|}{1} & & \multicolumn{3}{|c|}{0} \\
\hline \multicolumn{3}{|l|}{2} & & \multicolumn{3}{|c|}{4} \\
\hline \multicolumn{3}{|l|}{3} & & \multicolumn{3}{|c|}{6} \\
\hline \multirow{2}{*}{\multicolumn{3}{|c|}{$\begin{array}{l}4 \\
5\end{array}$}} & & \multicolumn{3}{|c|}{0} \\
\hline & & & & \multicolumn{3}{|c|}{1} \\
\hline \multirow{2}{*}{5} & \multicolumn{6}{|c|}{ Highest Treatment Required for Re-Emergence of Pneumonitis Without Rechallenge } \\
\hline & Treatment Hold & Oral & & teroids & Additional Immunosuppression* & Total \\
\hline 1 & 0 & & & & 0 & 0 \\
\hline 2 & 0 & & & & 0 & 4 \\
\hline 3 & 0 & & & & 2 & 6 \\
\hline 4 & 0 & & & & 0 & 0 \\
\hline 5 & 0 & & & & 1 & 1 \\
\hline \multirow[t]{3}{*}{ Total } & 0 & & & & 3 & 11 \\
\hline & & \multicolumn{5}{|c|}{ Clinical Outcomes of Re-Emergence of Pneumonitis Without Rechallenge } \\
\hline & Comple & Ived & Improved & Worsened & Unknown & Total \\
\hline \multicolumn{2}{|l|}{1} & & 0 & 0 & 0 & 0 \\
\hline \multicolumn{2}{|l|}{2} & & 3 & 0 & 0 & 4 \\
\hline \multicolumn{2}{|l|}{3} & & 2 & 2 & 0 & 6 \\
\hline \multicolumn{2}{|l|}{4} & & 0 & 0 & 0 & 0 \\
\hline \multirow{2}{*}{\multicolumn{2}{|c|}{$\begin{array}{l}5 \\
\text { Total }\end{array}$}} & & 0 & 1 & 0 & 1 \\
\hline & & & 5 & 3 & 0 & 11 \\
\hline
\end{tabular}

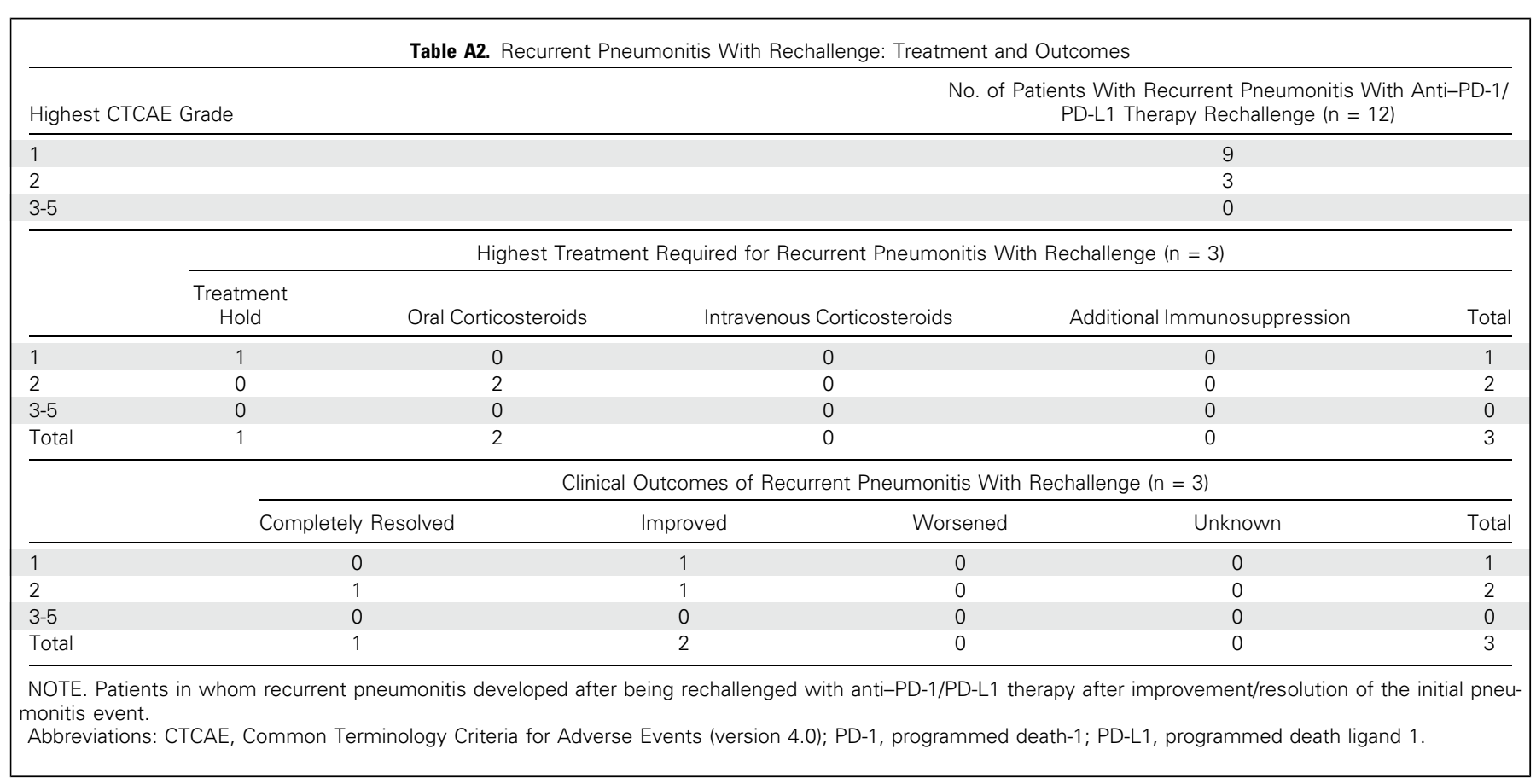


Pneumonitis With Anti-PD-1/PD-L1 Therapy

\begin{tabular}{|c|c|c|c|c|c|}
\hline Specimen Type & Procedure Type & Timing of Sample & Main Pathologic Finding & Radiologic Subtype & Other Sample \\
\hline Transbronchial biopsy & Bronchoscopy & Before corticosteroids & $\begin{array}{l}\text { Nondiagnostic (mild } \\
\text { chronic inflammation) }\end{array}$ & COP-like & NA \\
\hline $\begin{array}{l}\text { Transbronchial and } \\
\text { endobronchial biopsies }\end{array}$ & Bronchoscopy & After corticosteroids & Organizing pneumonia, CIP & COP-like & $\begin{array}{l}\text { Wedge resection: } \\
\text { organizing pneumonia } \\
\text { and fibrosis }\end{array}$ \\
\hline $\begin{array}{l}\text { Transbronchial and } \\
\text { endobronchial biopsies }\end{array}$ & Bronchoscopy & Before corticosteroids & CIP, granulomas & NOS & NA \\
\hline Bronchoscopic biopsy & Bronchoscopy & Before corticosteroids & $\begin{array}{l}\text { CIP with focal fibrin } \\
\text { (focal acute lung injury) }\end{array}$ & GGO & NA \\
\hline Transthoracic core biopsy & CT-guided core biopsy & After corticosteroids & $\mathrm{CIP}$, granulomas & Hypersensitivity & NA \\
\hline Transbronchial biopsy & Bronchoscopy & After corticosteroids & $\begin{array}{l}\text { Nondiagnostic (benign } \\
\text { bronchial mucosa) }\end{array}$ & COP-like & NA \\
\hline Transbronchial biopsy & Bronchoscopy & Before corticosteroids & $\begin{array}{l}\text { Nondiagnostic (benign } \\
\text { bronchial mucosa) }\end{array}$ & COP-like & NA \\
\hline Transbronchial biopsy & Bronchoscopy & After corticosteroids & Diffuse alveolar damage & GGO & NA \\
\hline $\begin{array}{l}\text { Transthoracic core biopsy and } \\
\text { transthoracic fine-needle } \\
\text { aspiration }\end{array}$ & CT-guided core biopsy & Before corticosteroids & $\begin{array}{l}\text { Organizing pneumonia, CIP, } \\
\text { eosinophils, vessels with } \\
\text { recanalized thrombi }\end{array}$ & NOS & NA \\
\hline Transbronchial biopsy & Bronchoscopy & Before corticosteroids & CIP, eosinophils & GGO & NA \\
\hline Wedge resection & Thoracoscopic surgery & Before corticosteroids & $\begin{array}{l}\text { Granulomatous inflammation, } \\
\text { organizing pneumonia }\end{array}$ & Interstitial & NA \\
\hline \multicolumn{6}{|c|}{$\begin{array}{l}\text { NOTE. Pathologic features of patients who underwent histopathologic assessment with lung biopsy for anti-PD-1/PD-L1 pneumonitis. Before corticosteroids indicates } \\
\text { lung biopsy performed before administration of corticosteroid medications, and After corticosteroids indicates lung biopsy performed after a minimum of } 1 \text { day of } \\
\text { corticosteroid therapy. } \\
\text { Abbreviations: CIP, cellular interstitial pneumonitis; COP, cryptogenic organizing pneumonia; CT, computed tomography; GGO, ground glass opacity; NA, not applicable; } \\
\text { NOS, not otherwise specified; PD-1, programmed death-1; PD-L1, programmed death ligand } 1 .\end{array}$} \\
\hline
\end{tabular}


Table A4. Association Between Clinicopathologic Features and Treatment Data With Clinical Outcomes of Pneumonitis

\begin{tabular}{|c|c|c|c|}
\hline \multirow[b]{2}{*}{ Clincopathologic Feature and Treatment Data } & \multicolumn{2}{|c|}{ Clinical Outcome* } & \multirow[b]{2}{*}{$P$} \\
\hline & $\begin{array}{c}\text { Resolved/ } \\
\text { Improved, } \\
\text { No. (\%) }\end{array}$ & $\begin{array}{c}\text { Worsened, } \\
\text { No. (\%) }\end{array}$ & \\
\hline No. of patients & 37 & 5 & \\
\hline No. of doses received & & & .99 \\
\hline$\leq 4$ & $20(54)$ & $3(60)$ & \\
\hline$>4$ & $17(46)$ & $2(40)$ & \\
\hline Smoking status & & & .053 \\
\hline Current/former & $18(49)$ & $5(100)$ & \\
\hline Never & $19(51)$ & 0 & \\
\hline Underlying lung condition & & & .047 \\
\hline No & $26(70)$ & $1(20)$ & \\
\hline Yes & $11(30)$ & $4(80)$ & \\
\hline Primary disease type & & & .18 \\
\hline Non-small-cell lung carcinoma & $5(14)$ & $3(60)$ & \\
\hline Melanoma & $24(65)$ & $2(40)$ & \\
\hline Hematologic malignancy & $4(11)$ & 0 & \\
\hline Other & $4(11)$ & 0 & \\
\hline Line of therapy & & & .99 \\
\hline 1 & $11(30)$ & $2(40)$ & \\
\hline 2 & $15(41)$ & $2(40)$ & \\
\hline$\geq 3$ & $11(30)$ & $1(20)$ & \\
\hline Prior chest radiation therapy & & & .99 \\
\hline No & $24(65)$ & $3(60)$ & \\
\hline Yes & $13(35)$ & $2(40)$ & \\
\hline Low DLCO at pneumonitis diagnosis $(n=12)$ & & & .99 \\
\hline No & $3(30)$ & 0 & \\
\hline Yes & $7(70)$ & $2(100)$ & \\
\hline Low FEV 1 at pneumonitis diagnosis $(n=16)$ & & & .99 \\
\hline No & $7(54)$ & $1(33)$ & \\
\hline Yes & $6(46)$ & $2(67)$ & \\
\hline Radiologic outcome & & & $<.001$ \\
\hline Resolved/improved & $37(100)$ & $1(20)$ & \\
\hline Worsened & $0(0)$ & $4(80)$ & \\
\hline Main pathologic pattern $(n=8)$ & & & .68 \\
\hline Cellular interstitial pneumonitis & $3(60)$ & $1(33)$ & \\
\hline Diffuse alveolar damage & 0 & $1(33)$ & \\
\hline Organizing pneumonia & $2(40)$ & $1(33)$ & \\
\hline Starting corticosteroid dose ( $\mathrm{n}=26$, prednisone equivalents) $\dagger, \mathrm{mg}$ & & & .32 \\
\hline$<60$ & 8 & 0 & \\
\hline $60-100$ & 6 & 2 & \\
\hline$>100$ & 7 & 3 & \\
\hline Time to commencement of corticosteroids ( $n=27$ ), days & & & .30 \\
\hline $0-4$ & 18 & 3 & \\
\hline$\geq 5$ & 4 & 2 & \\
\hline Length of corticosteroid taper $(n=26) \dagger$, days & & & .19 \\
\hline$<28$ & 2 & 2 & \\
\hline $28-56$ & 8 & 2 & \\
\hline$>56$ & 11 & 1 & \\
\hline Use of additional immunosuppression beyond corticosteroids & & & $<.001$ \\
\hline Yes & 0 & 5 & \\
\hline No & 37 & 0 & \\
\hline
\end{tabular}

NOTE. Associations between the clinicopathologic features of pneumonitis associated with anti-PD-1/PD-L1 monoclonal antibodies and the clinical outcomes of pneumonitis management by Fisher's exact test.

Abbreviations: DLCO, diffusing capacity of lung for carbon monoxide; FEV 1 , forced expiratory volume in 1 second; PD-1, programmed death-1; PD-L1, programmed death ligand 1.

* One patient was lost to follow-up and had an unknown clinical outcome of pneumonitis.

tFifteen patients were not treated with corticosteroids; in one patient, the starting corticosteroid dose was not known. 


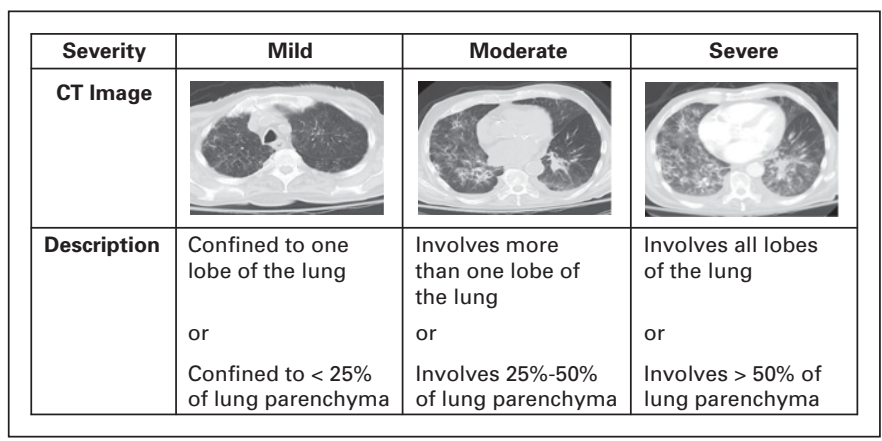

Fig A1. Radiologic severity of pneumonitis associated with anti-programmed death-1/programmed death ligand 1 therapy stratified into mild, moderate, and severe. CT, computed tomography.

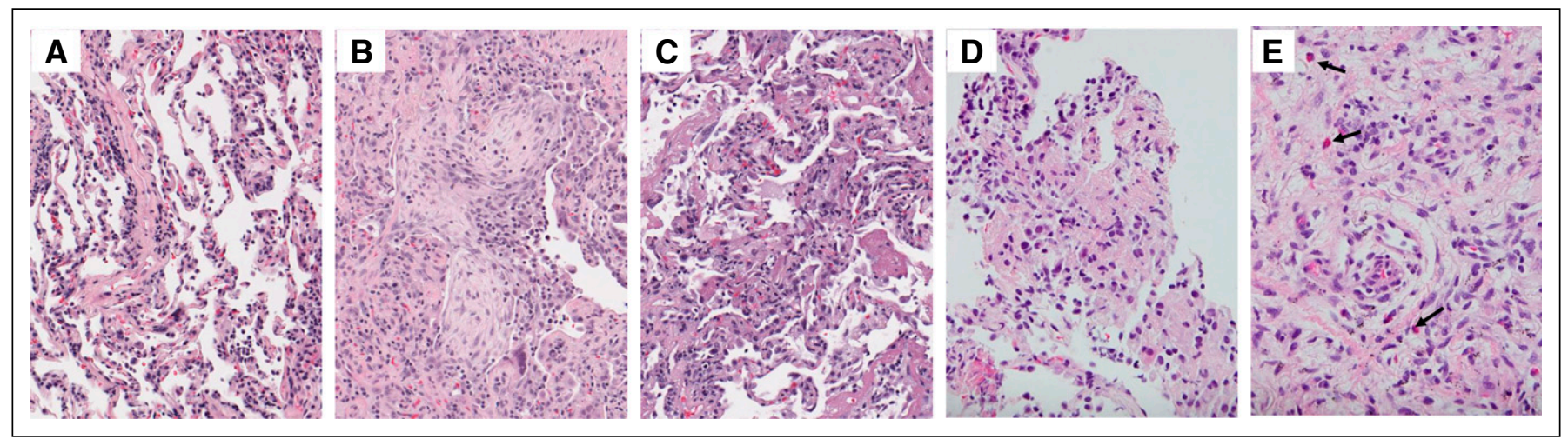

Fig A2. Histologic patterns of pneumonitis associated with anti-programmed death-1/programmed death ligand 1 therapy on lung biopsy (hematoxylin and eosin [HE] stain magnification, $\times 200$ ) included (A) cellular interstitial pneumonitis (mild case shown), (B) organizing pneumonia, and (C) diffuse alveolar damage. Additional findings (HE stain magnification, $\times 400$ ) include (D) poorly formed granulomas, and (E) eosinophils (arrows). 